\title{
Escala de atitudes frente à escola: validade fatorial e consistência interna
}

\author{
Medindo Atitudes Frente à Escola
}

\author{
Patrícia Nunes da Fonseca \\ Valdiney V. Gouveia \\ Rildésia S. V. Gouveia \\ Carlos Eduardo Pimentel \\ Emerson Diógenes de Medeiros
}

Resumo

Esta pesquisa objetivou adaptar a Escala de Atitudes frente à Escola (EAE), reunindo evidências de sua validade fatorial e consistência interna. Realizaramse dois estudos em João Pessoa. No Estudo I participaram 242 estudantes, a maioria de escolas particulares (53,7\%) e do sexo feminino (57,7\%), com idade média de 14,3. No Estudo 2 participaram 249 estudantes, predominando aqueles de escolas particulares (51\%) e do sexo feminino (54,6\%), com idade média de 14,6. Nos dois estudos, os participantes responderam a EAE e perguntas demográficas. No primeiro estudo, realizou-se uma análise de Componentes Principais em que se observou a existência de um fator, explicando 33,9\% da variância total $(\alpha=0,73)$. No segundo estudo, comprovou-se através da análise fatorial confirmatória que este modelo unifatorial era aceitável ( $A G F I=0,90$ e $R M S E A=0,08)$, com $\alpha=0,70$. Concluiu-se que esta medida pode ser empregada adequadamente em pesquisas no contexto em que foi adaptada.

Palavras-chave: atitudes; escolas; estudantes.

\section{School attitudes scale: factor validity and reliability}

\begin{abstract}
This research aimed at adapting the School Attitudes Scale (SAS), jointing evidences of its validity factor and reliability. Two studies were performed in João Pessoa (Paraíba). In Study I participants were 242 students, most of them from private schools (53.7\%) and female (57.7\%), with a mean age of 14.3 years old. In Study 2 participated 249 students, predominantly from private schools (5I\%) and female (54.6\%), with a mean age of 14.6 years old. Participants answered the SAS and demographic questions in both studies. In the first study, a Principal Component analysis indicated a unidimensional structure, accounting for $33.9 \%$ of the total variance $(\alpha=.73)$. In the second study, a confirmatory factor analysis revealed as acceptable the one-factor model $(A G F I=.90$, and RMSEA $=.08)$, with reliability of .70 . It was concluded that this measure can be adequately used in researches in the context where it was adapted.
\end{abstract}

Keywords: attitudes; schools; students.

\section{Escala de actitudes frente a la escuela: validez factorial y consistencia interna}

\section{Resumen}

Esta investigación tuvo como objetivo adaptar la Escala de Atitudes frente à Escola (EAE), reuniendo evidencias de su validez factorial y consistencia interna. Se realizaron dos estudios en João Pessoa. En el estudio I participaron 242 estudiantes, la mayoría de escuelas privadas (53,7\%) y del sexo femenino (57,7\%), con edad promedio de 14,3. En el Estudio 2 participaron 249 estudiantes, predominando los de escuelas privadas (5I\%) y del sexo femenino (54,6\%), con edad promedio de 14,6. En los dos estudios los participantes respondieron la EAE y preguntas demográficas. En el primer estudio se realizó un análisis de Componentes Principales en el cual se observó la existencia de un factor explicando 33,9\% de la variancia total $(\alpha=0,73)$. En el segundo estudio se comprobó, por medio del análisis factorial confirmatorio, que este modelo unifactorial era aceptable $(A G F I=0,90$ y $R M S E A=0,08)$, con $\alpha=0,70$. Se concluyó que esta medida puede ser empleada adecuadamente en investigaciones en el contexto para el cual fue adaptada. Palabras clave: actitudes; escuelas; estudiantes. 


\section{Introdução}

Em todas as culturas há sistemas organizados, de maior ou menor complexidade, que preparam os jovens para sua incorporação à sociedade. Entretanto, nas sociedades industriais desenvolvidas, as escolas são, por excelência, a instituição encarregada de transmitir conhecimentos, normas e valores da cultura, fontes basilares para o desenvolvimento adequado do jovem e da sua inserção à sociedade (Moreno \& Cubero, 1995). De acordo com a Lei de Diretrizes e Bases (LDB, 1996), a escola deve ter por finalidade desenvolver as competências dos alunos a fim de que os mesmos sejam capazes de refletir e intervir na realidade social, de forma a exercer ativamente sua cidadania. Por conseguinte, é na escola que a criança e os adolescentes constroem um conjunto de crenças sobre a sociedade, o contexto escolar, a relação professor - aluno e o processo de ensino-aprendizagem que irão subsidiar suas atitudes.

$\mathrm{Na}$ atualidade, Cavaliere (2002) aponta que a escola têm sido incumbida de assumir responsabilidades e compromissos educacionais bem mais amplos do que tradicionalmente o fez. Nestes casos, observa-se uma incorporação de responsabilidades que não são típicas da escola, mas que tem sido desenvolvida no contexto escolar. Aqui, incluem-se atividades relacionadas à higiene, à saúde, à alimentação e aos hábitos primários (por exemplo, lavar a mão, tomar banho, escovar os dentes). Além disso, constata-se, em grande parcela do alunado, uma dependência afetiva que faz dos professores pessoas de referência. Se tudo isto não bastasse, a escola ainda parece ter a incumbência, quase que exclusiva, de instruir os alunos na sua formação moral, pois, conforme Tiba (2002), os pais não estão cumprindo com o seu papel primordial de educar.

Esta situação fica patente quando se observam jovens com problemas de disciplina nas escolas ou ajustamento escolar, realidade cada dia mais corrente (Garcia, 1999). A propósito, Couto (2005) ressalta que $80 \%$ dos casos de alunos que apresentam comportamentos violentos na escola advém de problemas familiares, principalmente em virtude da falta de estrutura familiar adequada e da ausência de imposição de limites aos filhos.

Diante deste panorama, Cavaliere (2002) enfatiza que está havendo a ampliação do papel da escola, não por uma escolha político-educacional deliberada, mas por uma imposição da realidade social. Desta forma, a escola tem se tornado uma estrutura organizacional de grande importância na vida do estudante, a ponto de oferecer a base necessária para a formação acadêmica, afetiva e social. Não é de surpreender ao se constatar a fertilidade de pesquisas que abordam 0 contexto escolar como objeto de estudo. Na Psicologia do Desenvolvimento e na Psicologia Escolar/Educacional, os temas têm sido tratados sob diversos ângulos tais como: indisciplina (Couto, 2005; Garcia, 1999), dificuldade de aprendizagem (Oliveira \& Santos, 2005; Suehiro, 2006), estratégias de leitura (Capovilla, Capovilla \& Suiter, 2004), afetividade (Mahoney \& Almeida, 2005) e estilos de ensino (Cruz, Aguiar \& Barros, 2004). Na Psicologia Social, os estudos que têm o ambiente escolar como tema central são mais restritos e consideram predominantemente, por exemplo, as relações professor - aluno (Dell Prette, Dell Prette, Garcia \& Puntel, 1998), o ajustamento social e escolar (Conduct Problems Prevention Research Group, 1997; Sharma, Mcgue \& Benson, 1996; Sisto \& Pacheco, 2002), as atitudes dos estudantes frente a uma determinada disciplina (Silva, Brito, Cazorla \& Vendramini, 2002) e a influência do grupo na formação do jovem (Emílio, 2004).

Como uma instituição composta de uma diversidade de pessoas (diretores, supervisores, psicólogos, assistentes sociais, professores, alunos, serventes, etc.) que pensam, relacionam-se e influenciam-se mutuamente, a escola pode ser compreendida como um sistema social complexo. Nesta, entretanto, os depositários de todos os esforços precisam ser os alunos, atores transitórios que precisam se ajustar às regras ali definidas com o fim de avançar no sistema formal de ensino e ter possibilidades de um futuro melhor. Isso poderá depender, no entanto, de como os estudantes percebem ou reagem à escola, isto é, suas atitudes (Cheng \& Chan, 2003). Conhecer as atitudes que os estudantes apresentam frente à escola deveria contribuir para um melhor entendimento de alguns dos comportamentos 
presentes neste contexto educacional (por exemplo, agressão, altruísmo, entrosamento, desajustamento escolar, fracasso escolar).

\section{O estudo das atitudes no contexto educa- cional}

O estudo das atitudes há muito ocupa os psicólogos, tendo em vista este construto se relacionar diretamente com o comportamento, objeto último do seu interesse. Rodrigues (1994) define as atitudes como um conjunto das crenças, sentimentos e tendências comportamentais das pessoas frente a um determinado objeto. Em certa medida, elas determinam como as pessoas tomam uma posição frente aos outros, a algum acontecimento ou objeto específico. Segundo Myers (2000), as atitudes constituem um meio eficiente de avaliar o mundo, pois abrangem três dimensões: afeto (sentimentos), cognição (pensamentos) e comportamento (intenção), constituindo-se poderosos preditoras do comportamento.

As pesquisas sobre as atitudes no contexto escolar têm sido bastante diversificadas. Por exemplo, Silva e colaboradores (2002) procuraram verificar se as atitudes em relação à estatística poderiam estar correlacionadas com aquelas frente à matemática. Com outro enfoque, Colares e colaboradores (2002) visaram construir uma medida em que fosse possível conhecer as atitudes dos estudantes de Medicina frente a elementos relevantes ao exercício de sua profissão futura, como aspectos psicológicos e emocionais presentes nas doenças orgânicas e mentais, situações relacionadas à morte, atenção primária à saúde, doença mental e contribuição ao avanço científico da Medicina.

De certo modo, pesquisas como estas vêm mostrar um novo foco de interesse na área escolar ou da educação. Por mais de vinte anos estas estiveram voltadas, predominantemente, em abordar o desempenho acadêmico dos estudantes de uma forma mais objetiva (isto é, notas nos exames escolares), o que atendia ao interesse imediato de pensar e modificar as políticas públicas de educação. Atualmente, entretanto, embora este tema ainda ocupe espaço importante na agenda daqueles que fazem a educação, aspectos mais subjetivos dos estudantes têm recebido cada vez mais destaque, a exemplo da satisfação do estudante com a escola, das experiências vivenciadas e das atitudes apresentadas frente ao contexto escolar (Daly \& Defty, 200I), ou mesmo de seus estados emocionais e das variáveis de autopercepção ou eficácia enquanto aluno (Gouveia, Gaião e Barbosa, Gouveia \& Barbosa, 2004).

Coerente com esta linha de interesse, Willms (2003) constatou, em pesquisa realizada pelo Programa Internacional de Assistência ao Estudante, que os jovens que participavam mais das atividades oferecidas pela escola parecem ter melhor relação com seus colegas e administradores da escola, além de apresentar um bom desempenho acadêmico. Por outro lado, aqueles que apresentam atitudes negativas (por exemplo, agredir colegas), de desafeto com as pessoas inseridas na escola podem, gradualmente, vir a demonstrar comportamentos desajustados (por exemplo, brigas, repetência, envolvimento com drogas). Reforçando este aspecto, Duarte (2004) indica que a falta de envolvimento, interesse e vontade por parte dos jovens refletem seu descompromisso total frente às atividades da escola. Esta situação tem se agravado nos últimos anos e levado um número significativo de jovens a ter problemas com as drogas e de envolvimento em atos de violência no ambiente escolar.

Algumas pesquisas têm mostrado que as atitudes positivas dos estudantes em relação à escola compreendem um fator de ajustamento escolar entre os adolescentes, exercendo a função de elemento de proteção quanto à delinqüência e ao uso de substâncias proibidas (Cheng \& Chan, 2003; Conduct Problems Prevention Research Group, 1997; Sharma, Mcgue \& Benson, 1996). Desta feita, parece que as atitudes apresentadas pelos jovens frente à escola podem estar relacionadas a seu ajustamento escolar e, conseqüentemente, ao seu desempenho acadêmico.

Apesar de as atitudes frente à escola compreenderem um construto relevante, especialmente no que diz respeito à vida acadêmica do aluno, Cheng e Chan (2003) advertem que as poucas medidas existentes a respeito abordam aspectos específicos e diferentes do fenômeno como: engajamento educacional, aspirações educacionais, satisfação escolar, pertencimento escolar e atitudes escolares. Nenhuma medida prévia 
foi encontrada que considerasse os múltiplos elementos atitudinais, sejam eles, o cognitivo, o afetivo e o comportamental, que representam as atitudes (Myers 2000; Rodrigues, 1994). Neste contexto, Cheng e Chan (2003) propuseram uma medida que permitisse atender essas carências.

\section{Mensuração das atitudes frente à escola}

Em uma revisão da literatura, dois buscadores foram considerados: Index Psi (2006) e Google Acadêmico (2006), inserindo-se a expressão "atitudes frente à escola". Como resultado, encontraram-se 15 publicações nacionais; destas, quatorze foram prontamente descartadas por não apresentarem relação com o tema objeto de interesse; e uma única, uma tese de doutorado, dizia respeito à atenção e sua relação com as atitudes de crianças no contexto escolar (Tonelotto, 1998), mas não apresentou qualquer instrumento de medida deste construto. Portanto, parece evidente a não existência de instrumento publicado em que se pretendesse avaliar as atitudes dos estudantes frente à escola no contexto brasileiro. Isso motivou adaptar a School Attitudes Scale (Cheng \& Chan, 2003), cujos estudos de elaboração e descrição dos seus parâmetros psicométricos são relatados a seguir. A propósito, realizaram-se dois estudos.

Estudo I. Procurou-se conhecer evidências acerca da estrutura fatorial, consistência interna (Alfa de Cronbach) e validade convergente-discriminante desta medida. 2.105 estudantes do ensino médio de Wanchai (Hong Kong), com idade média de 14,8 anos $(D P=1,58)$, sendo a maioria do sexo feminino $(61,7 \%)$. Estes responderam a Escala de Atitudes frente à Escola e indicaram, em uma escala de sete pontos, variando de 0 (Nenhuma vez) a 6 (Mais de dez vezes), com que freqüência eles apresentaram alguns comportamentos (por exemplo, gazear aulas, participar de atividades extracurricular) nos últimos três meses. Através da análise fatorial confirmatória, seus autores reuniram provas da adequação desta medida como sendo unifatorial, com saturações variando de 0,50 a 0,67, e índices de ajuste satisfatórios, CFI (Comparative Fit Index) $=0,94$ e RMSR (Root Mean Square Error of Approximation) $=0,068$; seu Alfa de Cronbach foi 0,8I. Atestando sua validade convergente, esta escala se correlacionou $(p<0,00 \mathrm{I})$ com estudar junto com colegas $(+)$, participar de atividades extracurricular $(+)$, pegar livros emprestados na biblioteca (+), argumentar com professores desrespeitando-os em público (-) e gazetear aulas (-); e, finalmente, sua validade discriminante se comprovou no sentido de que suas pontuações não se correlacionaram $(p>0,05)$ com brincar no parque e confidenciar segredos aos amigos.

Estudo 2. Este teve por objetivos verificar a estabilidade temporal das pontuações desta escala (testereteste) e sua correlação com a medida de desempenho acadêmico. $15 \mathrm{I}$ estudantes com idade média de 15 anos $(D P=I, 92)$ participaram. O tempo transcorrido entre as duas aplicações foi de duas a quatro semanas. Durante o reteste, os participantes indicavam a percepção de seu desempenho acadêmico em três disciplinas (inglês, chinês e matemática), considerando uma escala de cinco pontos, com três âncoras: $I$ = Abaixo da média, $2=$ Na média e $3=$ Acima da média. As pontuações para estas três "avaliações" foram somadas, produzindo uma medida de percepção de desempenho global, possibilitando comparar os participantes. Sumariamente, a escala demonstrou ter estabilidade temporal (precisão teste-reteste), com correlações variando de 0,73 (intervalo de duas semanas) a 0,68 (intervalo de quatro semanas); as pontuações nesta medida se correlacionaram diretamente com aquela de percepção de desempenho global $(r=0,25 ; p<0,0$ l $)$.

Em resumo, os estudos acima descritos permitiram reunir evidências em favor da validade fatorial e convergente-discriminante da Escala de Atitudes frente à Escola, que também mostrou consistência interna e estabilidade temporal aceitável. Apesar destes aspectos favoráveis desta medida, além de contar com a vantagem de ser curta, formada por apenas nove itens, favorecendo seu uso em pesquisa que considera outras medidas e/ou que pretendam comparar culturas (Gosling, Rentfrow \& Swann Jr., 2003), nenhum estudo foi encontrado em que esta tivesse sido adaptada ou empregada ao contexto brasileiro. Neste sentido, o presente artigo pretende justamente conhecer evidências de validade fatorial e consistência interna da versão brasileira desta medida. Complementarmente, avalia-se se suas pontuações 
são influenciadas por variáveis de natureza demográfica (por exemplo, sexo, idade). Para a consecução destes objetivos, decidiu-se realizar dois estudos, descritos a seguir.

\section{Estudo I - Análise exploratória da escala atitudes frente à escola}

Este estudo procurou averiguar que estrutura fatorial poderia ser mais adequada para representar a Escala de Atitudes frente à Escola. Neste sentido, deuse ênfase a procedimentos de natureza mais exploratória, chegando à adequação de se realizar uma análise fatorial e checando o número de dimensões que poderiam ser obtidas.

\section{Método}

\section{Participantes}

Tratou-se de uma amostra de conveniência (nãoprobabilística). 242 estudantes provenientes de escolas particulares $(53,7 \%)$ e públicas $(46,3 \%)$ da cidade de João Pessoa, PB participaram voluntariamente. A maioria era do sexo feminino $(57,7 \%)$, com idades variando entre II a 20 anos $(M=14,3 ; D P=1,88)$. Esta variável foi transformada em faixa etária, com a seguinte distribuição: até 13 anos compreenderam $32,5 \%$, de 14 e $15,39,56 \%$ e, finalmente, com 16 ou mais anos, $28,9 \%$. Com relação à escolaridade, $23,2 \%$ e $38,4 \%$ cursavam, respectivamente, a sexta e oitava séries do ensino fundamental, e outros $38,4 \%$, o segundo ano do ensino médio.

\section{Instrumentos}

Escala de Atitudes frente à Escola. Este instrumento foi originalmente proposto por Cheng e Chan (2003), sendo previamente detalhados os estudos que o embasaram e os parâmetros psicométricos observados. Compõe-se de nove itens (por exemplo, Sinto que sou parte da escola; A vida escolar é chata e desinteressante), respondidos em escala tipo Likert, de cinco pontos, variando de $I=$ Discordo totalmente a 5 = Concordo totalmente.

Empregou-se o método de back translation com o fim de criar a versão em português desta medi- da. Neste sentido, inicialmente esta foi traduzida do inglês para o português por um pesquisador bilíngüe, e logo esta versão foi traduzida novamente para $\circ$ inglês por uma professora do curso de Letras, com habilitação em Língua Inglesa. Seguiu-se, finalmente, a comparação das duas versões em inglês, contando com a colaboração de uma terceira pessoa, também bilíngüe. Nenhuma modificação substancial foi observada, mantendo-se os significados do que se pretendia expressar com cada item. Deste modo, atestou-se a pertinência da versão em português da Escala de Atitudes frente à Escola. Contudo, antes de aplicá-la, procedeu-se à validação semântica. $\mathrm{Na}$ oportunidade consideramse 20 estudantes da sexta série do ensino fundamental de uma escola pública. Procurou-se verificar se os itens e o formato da escala de respostas eram compreensíveis.

Informações Demográficas. Os participantes também responderam quatro perguntas de natureza demográfica, a saber: idade, sexo, escolaridade e tipo de escola (pública ou privada).

\section{Procedimento}

Os pesquisadores entraram em contato com as direções das escolas escolhidas, por conveniência a fim de obter permissão para aplicar os questionários. Após seu consentimento, a aplicação foi efetuada por dois colaboradores devidamente treinados. As turmas foram escolhidas pelo pesquisador e, conforme a disponibilidade dos professores e do quadro de aulas, a aplicação ia sendo realizada em ambiente coletivo de sala de aula. No caso, os colaboradores se apresentavam e solicitavam a participação dos estudantes no sentido de responderem individualmente o questionário, identificado como pretendendo conhecer como pensavam e agiam no seu dia-a-dia. Indicou-se que a participação seria voluntária, sendo assegurado a todos o anonimato. Deram-se oralmente as instruções gerais de como proceder no preenchimento dos questionários; os colaboradores permaneceram em sala de aula durante toda a coleta, disponibilizando-se a esclarecer eventuais dúvidas dos estudantes. $O$ tempo médio para concluir a participação no estudo foi de aproximadamente 15 minutos. 


\section{Análises de Dados}

Para a tabulação e as análises estatísticas dos dados foi utilizado o SPSS (versão 13). Estatísticas descritivas (medidas de tendência central e dispersão) foram calculadas e efetuadas análises de Componentes Principais. Neste caso, procurou-se previamente conhecer a adequação de se realizar este tipo de análise, considerando dois critérios: Kaiser-Meyer-Olkim $(K M O)$, que precisa ser de ao menos 0,60 para suportar este tipo de análise, e o Teste de Esfericidade de Bartlett, cujo valor do qui-quadrado necessita ser estatisticamente significativo (Tabachnick \& Fidell, 1996). Realizou-se ainda uma análise paralela para averiguar o número de componentes a extrair (O'Connor, 2000). Finalmente, a consistência interna (Alfa de Cronbach) da estrutura resultante foi calculada, e decidiu-se realizar uma ANOVA univariada para conhecer o efeito de variáveis demográficas nas pontuações desta escala.

\section{Resultados}

Inicialmente, comprovou-se a adequação de se realizar uma análise fatorial com a matriz de correlações entre os itens que compõem a medida analisada. Os indicadores observados são favoráveis à realização desta análise visto que as correlações parciais não são suficientemente grandes $(K M O=0,79)$ e pode-se rejeitar a hipótese nula de que a matriz de correlações é de identidade com valores próximos a zero, fora da diagonal $\left[\chi^{2}(36)=393,64 ; p<0,00 \mathrm{I}\right)$. Deste modo, com o fim de conhecer o número de dimensões da Escala de Atitudes frente à Escola no contexto brasileiro, decidiu-se efetuar uma análise de Componentes Principais $(P C)$, sem fixar o número de componentes a extrair. Três critérios foram levados em conta: quantidade de valores próprios (eigenvalues) iguais ou superiores a I (Critério de Kaiser), distribuição gráfica dos valores próprios, tomando como referência $\circ$ ponto a partir do qual nenhum outro componente aporta consideravelmente para a estrutura (Critério de Cattell) e análise paralela. Neste caso, tomou-se em conta os parâmetros do banco de dados original, considerando 242 participantes e nove itens/variáveis, realizando 1000 simulações. Adicionalmente, teve-se em conta a interpretabilidade da estrutura resultante. Os resultados destas análises estão sumarizados na Figura I.

Como se pode constatar, dois componentes apresentaram valores próprios que atendem o critério de Kaiser. Especificamente, os componentes tiveram valores próprios de 3,05 e I,19, respectivamente, explicando conjuntamente $47,1 \%$ da variância total. Não obstante, o critério de Cattell não é suficientemente esclarecedor; no caso, podem ser defendidas as estruturas uni e bi-fatorial. Neste contexto, a análise paralela é mais robusta. $O$ primeiro e o segundo componentes gerados aleatoriamente apresentam os valores próprios de I,3। e I,20, respectivamente. Este último é superior ao segundo que foi observado na análise $P C$, corroborando a pertinência de se extrair um único componente. Esta estrutura é coerente com o modelo inicialmente proposto pelos autores da medida considerada, sendo assim defensável. Desta feita, decidiu-se fazer novamente uma $P C$, atendendo a esta recomendação. Os resultados são mostrados na Tabela I.

De acordo com esta tabela, o componente único solicitado apresentou saturações geralmente acima de |0,40|; a exceção foi o item 7 (Vale a pena ir à escola, mesmo que isso não me ajude a conseguir um emprego), cuja saturação foi 0,27 . Contudo, esta corresponde a uma correlação estatisticamente diferente de zero $(t=4,34 ; p<0,00 \mathrm{I})$. Portanto, decidiuse não excluí-lo. A estrutura unidimensional observada apresentou valor próprio de 3,05 , explicando 33,9\% da variância total. Seu índice de consistência interna (Alfa de Cronbach) se situou em 0,73.

Conhecendo a estrutura unidimensional deste instrumento, criou-se uma pontuação total (somatório de todos os seus nove itens), permitindo conhecer em que medida os jovens estudantes variam em suas atitudes frente à escola em função de características demográficas. No caso, estas pontuações entraram como variável critério, considerando o efeito principal de quatro variáveis antecedentes: idade, sexo, escolaridade e tipo de escola. Uma ANOVA univariada foi realizada, tendo revelado efeito entre os sujeitos unicamente para a variável faixa etária $[F(2$, 


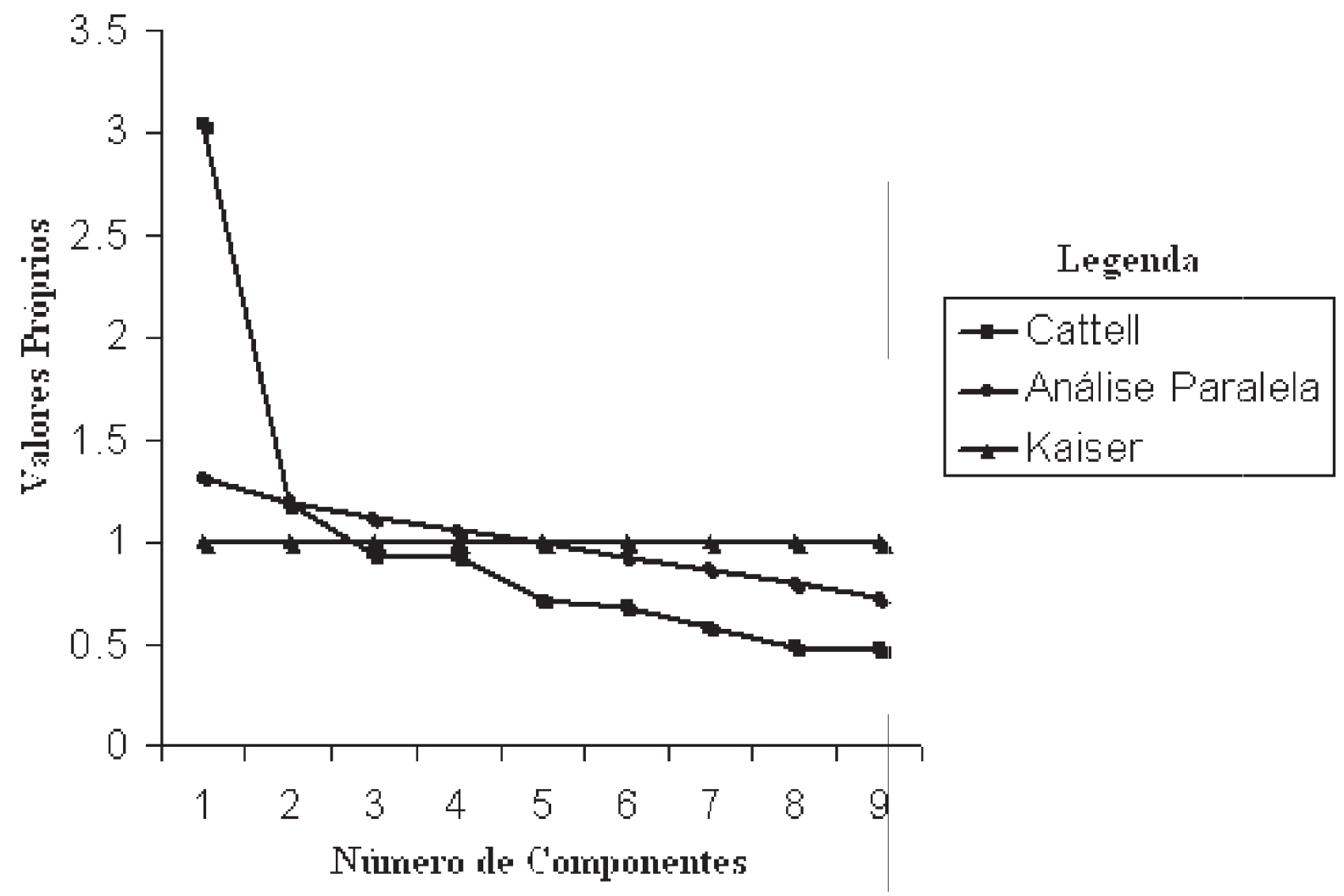

Figura I. Distribuição Gráfica dos Valores Próprios da Escala de Atitudes frente à Escola.

Tabela I. Estrutura Fatorial da Escala de Atitudes Frente à Escola.

\begin{tabular}{|c|c|c|c|}
\hline Itens & Descrição do conteúdo & Componente & $h^{2}$ \\
\hline 09 & Sinto que sou parte da escola. & $0,72 *$ & 0,52 \\
\hline 05 & A vida escolar é chata e desinteressante. & $-0,68^{*}$ & 0,46 \\
\hline 02 & O colégio tem me dado um sentido de realização pessoal. & $0,65^{*}$ & 0,42 \\
\hline 01 & Acredito que a escola pode me ajudar a ser uma pessoa madura. & $0,60 *$ & 0,36 \\
\hline 03 & Empenho-me bastante para aprender muitas coisas. & $0,60^{*}$ & 0,36 \\
\hline 06 & Participo ativamente da vida escolar. & $0,59 *$ & 0,35 \\
\hline 08 & $\begin{array}{l}\text { Se tivesse oportunidade de escolher, deixaria a escola e } \\
\text { conseguiria emprego. }\end{array}$ & $-0,53 *$ & 0,28 \\
\hline 04 & Considero sem importância as coisas que tenho feito na escola. & $-0,48^{*}$ & 0,23 \\
\hline 07 & $\begin{array}{l}\text { Vale a pena ir à escola, mesmo que isso não me ajude a } \\
\text { conseguir um emprego. }\end{array}$ & 0,27 & 0,07 \\
\hline \multicolumn{2}{|c|}{ Número de itens } & 9 & \\
\hline \multicolumn{2}{|c|}{ Valor Próprio } & 3,05 & \\
\hline \multicolumn{2}{|c|}{ \% da Variância } & 33,90 & \\
\hline \multicolumn{2}{|c|}{ Alfa de Cronbach $(\alpha)$} & 0,73 & \\
\hline
\end{tabular}

Nota: *carga fatorial comumente aceita para interpretações dos componentes, $|0,30|$ 
$2 \mid 2)=3,46 ; p=0,03]$; porém, o teste post hoc de Bonferroni mostrou inexistir diferenças significativas entre as três faixas etárias no que se refere às atitudes frente à escola. Todas as demais variáveis apresentaram um $F<I, 00$.

Em resumo, estes resultados parecem indicar evidências de validade fatorial e consistência interna da Escala de Atitudes frente à Escola. Não obstante, reconhece-se aqui o caráter essencialmente exploratório da técnica estatística empregada $(P C)$. As variáveis demográficas parecem ser pouco preponderantes para explicar as atitudes dos participantes frente à escola. Deste modo, planejou-se realizar uma nova pesquisa, contando com um mínimo de 200 participantes com características demográficas próximas aos deste estudo, efetuando uma análise fatorial confirmatória da estrutura desta medida. Este estudo é descrito a seguir.

\section{Estudo 2 - Testando a estrutura unidimensional da escala atitudes frente à escola}

Neste segundo estudo procurou-se, primordialmente, comprovar em que medida se poderia assumir adequadamente a estrutura de um único componente para descrever a Escala de Atitudes frente à Escola. Não obstante, este compreende igualmente uma ocasião para checar a consistência interna desta medida e avaliar se suas pontuações são influenciadas por características demográficas dos participantes.

\section{Método}

\section{Participantes}

Participaram deste estudo 249 estudantes provenientes de escolas públicas (49\%) e particulares (51\%) da cidade de João Pessoa, PB. Destes, 30,1\% e $3 \mathrm{I}, 7 \%$, respectivamente, cursavam a sexta e sétima séries do ensino fundamental, e os restantes $38,2 \%$ cursavam o segundo ano do ensino médio. A maioria indicou ser do sexo feminino $(55,1 \%)$, com idades variando entre II a 20 anos $(M=14,6 ; D P=2,12)$. Esta variável, como no estudo anterior, foi transformada, compondo-se de três categorias: até 13 anos
$(31,4 \%), 14$ e 15 anos $(32,6 \%)$ e 16 ou mais anos (36\%).

\section{Instrumento}

Os participantes responderam a Escala de Atitudes frente à Escola e o mesmo conjunto de perguntas demográficas previamente descrito.

\section{Procedimento}

A aplicação ocorreu em ambiente coletivo de sala de aula, porém individualmente. Procurou-se seguir os mesmos passos do estudo anterior, inclusive contando com os dois colaboradores anteriormente recrutados.

\section{Análise dos Dados}

Para realização da análise fatorial confirmatória, empregou-se o AMOS (versão 4); no caso, pretendeu-se testar a adequação do modelo unidimensional. Considerou-se como entrada a matriz de covariâncias, tendo sido adotado o estimador ML (Maximum Likelihood). Este tipo de análise estatística é mais criterioso e rigoroso do que o anterior ( $P C$ ), permitindo testar diretamente uma estrutura teórica, como é o caso da proposta por Cheng e Chan (2003). Esta análise apresenta alguns índices que permitem avaliar a qualidade de ajuste do modelo proposto (ver Byrne, 1989; Garson, 2003; Kelloway, 1998; Tabachnick \& Fidell, 1996; van de Vijver \& Leung, 1997):

O $\chi^{2}$ (qui-quadrado) testa a probabilidade de 0 modelo teórico se ajustar aos dados; quanto maior este valor pior o ajustamento. Este tem sido pouco empregado na literatura, sendo mais comum considerar sua razão em relação aos graus de liberdade $\left(\chi^{2} / g\right.$.I.). Neste caso, valores até 3 indicam um ajustamento adequado.

O Goodness-of-Fit Index (GFI) e o Adjusted Goodness-of-Fit Index (AGFI) são análogos ao $R^{2} \mathrm{em}$ regressão múltipla. Portanto, indicam a proporção de variância-covariância nos dados explicada pelo modelo. Estes variam de 0 a I, com valores na casa dos 0,80 e 0,90 , ou superior, indicando um ajustamento satisfatório.

A Root-Mean-Square Error of Approximation (RMSEA), com seu intervalo de confiança de $90 \%$ 
(IC90\%), é considerado um indicador de "maldade" de ajuste, isto é, valores altos indicam um modelo não-ajustado. Assume-se como ideal que o RMSEA se situe entre 0,05 e 0,08, aceitando-se valores de até 0,10 (Garson, 2003; Kelloway, 1998).

\section{Resultados}

Assumindo que todos os itens da Escala de Atitudes frente à Escola saturam em um único fator, decidiu-se testar este modelo. Os resultados estão sumarizados na Figura 2 a seguir.
Todas as saturações (lambdas, $\lambda$ ) ou pesos de regressão são estatisticamente diferentes de zero (0; $t>1,96 ; p<0,05)$, sugerindo a pertinência do conjunto de itens considerados. Os indicadores de qualidade de ajuste do modelo uni-fatorial podem ser considerados satisfatórios, como seguem: $\chi^{2} / g \mid=2,59$, $G F I=0,94, \quad A G F I=0,90, \quad C F I=0,86$ e $R M S E A$ $(90 \% / C)=0,08(0,06-0,10)$. A consistência interna (Alfa de Cronbach) para este fator único foi 0,70.

Finalmente, a pontuação total dos participantes na Escala de Atitudes frente à Escola foi considerada como variável critério em uma ANOVA, tendo sido incluídas como variáveis antecedentes às quatro analisadas no

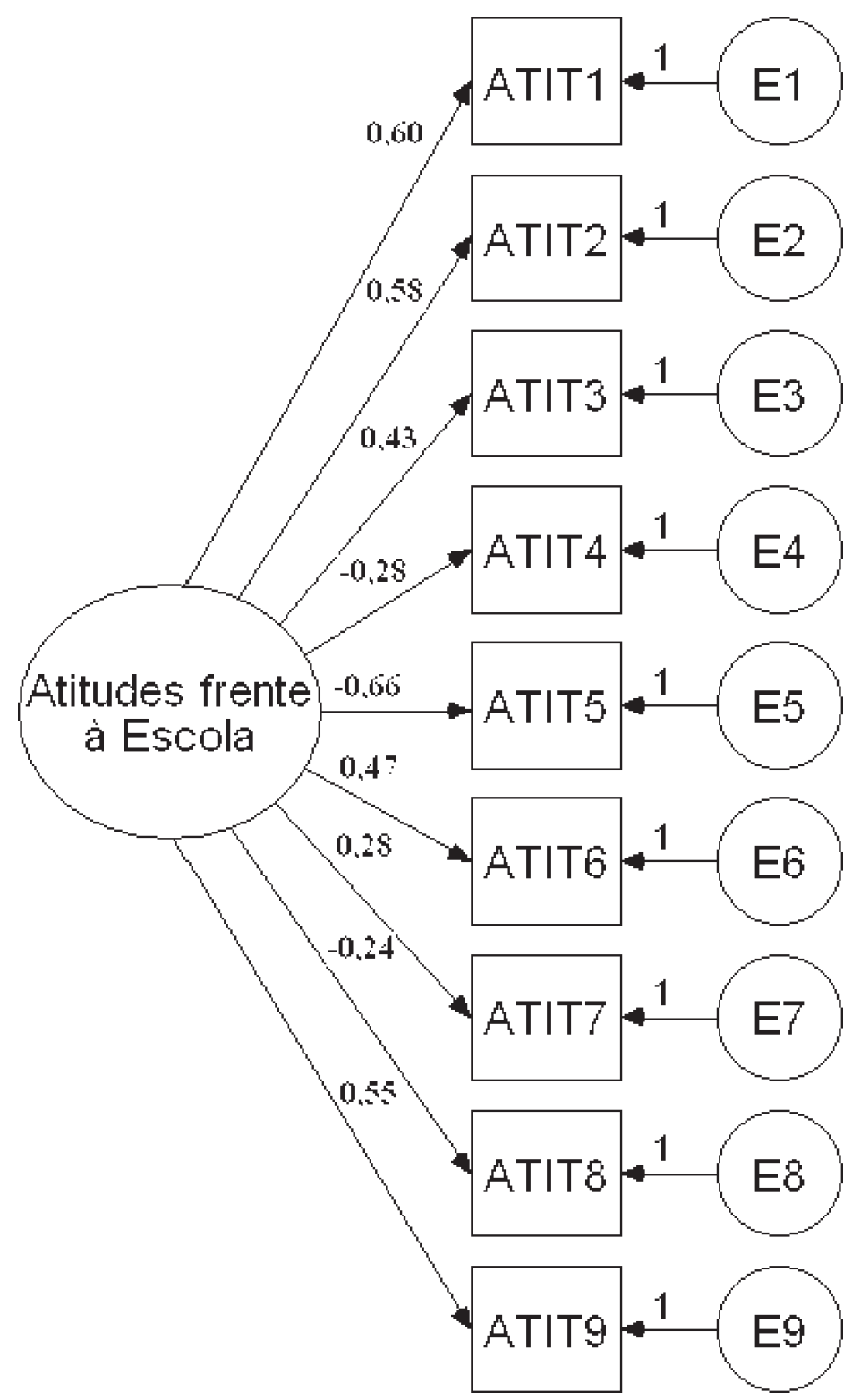

Figura 2. Estrutura Fatorial da Escala de Atitudes frente à Escola. 
estudo prévio, isto é, faixa etária, sexo, escolaridade e tipo de escola. Unicamente, a variável sexo do participante se revelou estatisticamente significativa para diferenciar suas atitudes frente à escola $[F(I, \mid 84)=10,25 ; p=0,002, d=0,05]$. O teste post hoc de Bonferroni indicou que os participantes do sexo feminino apresentaram atitudes mais favoráveis frente à escola $(M=34,7)$ do que aqueles do sexo masculino $(M=32,5), p<0,05$. As demais variáveis demográficas não revelaram efeito principal nas pontuações dos participantes, $F<1,60 ; p>0,05$.

\section{Discussão}

A presente pesquisa teve como objetivo principal adaptar a Escala de Atitudes frente à Escola para o contexto brasileiro, conhecendo evidências de sua validade fatorial e consistência interna; procurou ainda verificar se suas pontuações variam de acordo com algumas variáveis demográficas (por exemplo, sexo, idade). Espera-se que estes tenham sido alcançados. Não obstante, cabe apontar limitações potenciais desta pesquisa que, embora não a invalidem ou comprometam seus objetivos, demandam pensar criticamente os resultados previamente descritos. Por exemplo, incluíram-se amostras de conveniência, não sendo representativas da população brasileira nem mesmo da pessoense. Contudo, não foi o propósito do estudo assegurar validade externa dos resultados (generalização), mas conhecer os parâmetros psicométricos desta escala. Neste sentido, as duas amostras atendem ao critério mínimo de 200 participantes, requeridos para análises estatísticas mais avançadas a exemplo da análise fatorial confirmatória (Watkins, 1989). Discutem-se a seguir os principais resultados.

Na definição do número de fatores a serem extraídos, adotaram-se diversos critérios (Kaiser, Cattell, análise paralela; Hayton, Allen \& Scarpello, 2004), tendo sido corroborada a adequação de assumir um modelo unifatorial, coerente com o que descrevem Cheng e Chan (2003). A análise PC no Estudo I revelou um componente geral claramente na linha observada por estes autores; um único item (7. Vale a pena ir à escola, mesmo que isso não me ajude a conseguir um emprego) apresentou saturação abaixo da magnitude comumente recomendada $(|0,30|$; Gorsuch, 1983), embora estatisticamente diferente de zero. Cabe assinalar que este item reúne algumas propriedades semânticas não recomendadas [por exemplo, é relativamente mais cumprido do que os demais; é condicional (mesmo que) e contém uma negação (não me ajude); ver Pasquali, 2003. Reescrever este item ou substituí-lo por outro pode contribuir, por exemplo, para tornar mais clara a estrutura fatorial desta medida.

No Estudo 2 foi realizada uma análise fatorial confirmatória que reforçou a adequação da estrutura unifatorial. Os indicadores de qualidade de ajuste deste modelo são muito próximos daqueles relatados quando do estudo original de criação desta escala (Cheng \& Chan, 2003, p. 1065), atendendo recomendações apresentadas na literatura (Byrne, 1989; Garson, 2003; Kelloway, 1998; Tabachnick \& Fidell, 1996; van de Vijver \& Leung, 1997) como seguem: $\chi^{2} / g \mid=2,59$, $G F I=0,94, \quad A G F I=0,90, \quad C F I=0,86$ e RMSEA $(90 \% / C)=0,08(0,06-0,10)$. A consistência interna (Alfa de Cronbach) para este fator único foi 0,70.

Quanto à precisão (consistência interna) da Escala de Atitude frente à Escola, avaliado através do coeficiente Alfa de Cronbach $(\alpha)$, procedimento comum e prático de checagem deste parâmetro no marco da Teoria Clássica dos Testes - TCT (Ledesma, Ibañez \& Mora, 2002), os valores observados nos Estudos I e 2 são algo inferiores àqueles encontrados por Cheng e Chan (2003). Contudo, devem ser encarados como satisfatórios; cumprem a rule of thumb de ser ao menos 0,70 (Nunnally, 1991; Oviedo \& Campo-Árias, 2005), sendo plenamente aceitáveis quando se trata de medida empregada com fins de pesquisa (Clark \& Watson, 1995; Mueller, 1986), como parece ser o presente caso. Outros dois aspectos animam pensar com otimismo acerca deste parâmetro: (I) a escala não é dispendiosa, contando com menos de dez itens; e (2) o construto tratado é atitudinal, sendo menos estável do que se fossem traços de personalidade ou habilidades. Nestas circunstâncias é comum observar menores coeficientes Alfas de Cronbach (Ledesma \& cols., 2002; Nunnally, 199I; Pasquali, 2003). 
Comprovou-se também que as pontuações da Escala de Atitudes frente à Escola não dependem de variáveis demográficas, haja vista que nenhuma variável conseguiu explicar as diferenças em suas pontuações através dos dois estudos. É possível que tais atitudes tenham mais em comum com os valores que guiam a vida dos jovens estudantes ou as metas de realização por estes adotadas. Cheng e Chan (2003) constataram que as pontuações dos participantes nesta medida conseguiram explicar sua percepção de desempenho global. Recentemente, Gouveia e cols. (2007) constataram que jovens estudantes do ensino médio que pontuaram alto em metas de aprendizagem-aproximação se percebiam como bons estudantes e relatavam maiores notas nas disciplinas Português e Matemática. Contudo, esta presumível relação entre as atitudes frente à escola e as metas de realização precisam ser empiricamente comprovadas, demandando estudos futuros.

Finalmente, a propósito de novos estudos, caberia replicar o estudo de Cheng e Chan (2003) no que se refere à estabilidade temporal (teste-reteste) e validade convergente-discriminante. Quanto a este último aspecto, poder-se-ia correlacionar (validade convergente) as atitudes frente à escola com medidas de engajamento ou ajustamento escolar (Conduct Problems Prevention Research Group, 1997; Sharma \& cols., 1996; Sisto \& Pacheco, 2002). Caberia também ter em conta medidas comportamentais (por exemplo, notas obtidas nos exames, número de faltas, reclamações recebidas na coordenação da escola), correlacionando-as com as pontuações nesta medida. Poder-se-ia, igualmente, correlacionar tais atitudes com alguma medida de desejabilidade social (validade discriminante), descartando este traço como um viés de resposta, freqüentemente presente em medidas de tipo auto-relato (Ribas Jr., Moura, \& Hutz, 2004), como a que aqui é considerada.

\section{Referências}

Byrne, B. M. ( 1989). A primer of LISREL: Basic applications and programming for confirmatory factor analytic models. New York: Springer-Verlag.
Capovilla, A. G. S., Capovilla, F. C., \& Suiter, I. (2004). Processamento cognitivo em crianças com e sem dificuldades de leitura. Psicologia em Estudo, 9, 449-458.

Cavaliere, A. M. V. (2002) Educação integral: uma nova identidade para a escola brasileira? Educação \& Sociedade, 23(8I), 247-270.

Cheng, S. T., \& Chan, A. C. M. (2003). The development of a brief measure of school attitude. Educational and Psychological Measurement, 63, 1060-1070.

Clark, L. A., \& Watson, D. (1995). Constructing validity: Basic issues in objective scale development. Psychological Assessment, 7, 309-319.

Colares, M. F. A., Troncon, L. E. A., Figueiredo, J. F. C., Cianflone, A. R. L., Rodrigues, M. L. V., Piccinato, C. E., Peres, L. C., \& Coleta, J. A. D. (2002). Construção de um instrumento para avaliação das atitudes de estudantes de medicina frente a aspectos relevantes da prática médica. Revista Brasileira de Educação Médica, 26, 194-203.

Couto, S. C. S. (2005). Professores são vítimas de agressões de alunos em sala de aula. Disponível: $h$ ttp://rmtonline.globo.com/ $\mathrm{mt} / \mathrm{rmtespecial} /$ materia.htm?id = I I 3 / IO (consultado em 26 de janeiro de 2007).

Conduct Problems Prevention Research Group (CPPRG). (1997). School adjustment - Child (Revised). Disponível: http:/ /www.fasttrackproject.org/ (consultado em I 2 de abril de 2004).

Cruz, O., Aguiar, C., \& Barros, S. (2004). Escala de Avaliação dos Estilos de Ensino: Qualidades psicométricas dos dados. Psico-USF, 9, I65-171.

Daly, P., \& Defty, N. (200I). A longitudinal study of secondary school students' attitudes to school life: gender and school gender influences. Third Internacional, Inter-disciplinary Evidence-Based Policies and Indicator Systems Conference, CEM Centre, University of Durham [On-line]. Disponível: http://www.cemcentre.org/Documents/ (consultado em 10 de Janeiro de 2007).

Dell Prette, Z. A. P., Dell Prette, A. G., Garcia, A. T. B., \& Puntel, L. P. (1998). Habilidades sociais do professor em sala de aula: Um estudo de caso. Psicologia Reflexão e Crítica, I I, 59 I-603.

Duarte, V. C. (2004). Relações interpessoais: Professor e aluno em cena. Psicologia Educacional, 19(1), II9-142.

Emílio, S. A. (2004). A escola como grupo e os grupos na escola. Revista SPAGESP, 5, 24-28.

Garcia, J. (1999). Indisciplina na escola: Uma reflexão sobre a dimensão preventiva. Revista Paranaense de Desenvolvimento, $95,101-108$. 
Garson, G. D. (2003). PA 765 Statnotes: An online textbook. Disponível: http://www2.chass.ncsu.edu/garson/pa765/ statnote.htm (consultado dia 17 de maio de 2005).

Google Acadêmico. (2007). Atitudes frente à escola. Disponível: http://scholar.google.com.br/ (consultado em I5 de janeiro de 2007).

Gorsuch, R. L. (1983). Factor analysis. Hillsdale: Lawrence Erlbaum.

Gosling, S. D., Rentfrow, P. J., \& Swann Jr., W. B. (2003). A very brief measure of the Big-Five personality domains. Journal of Research in Personality, 37, 504-528.

Gouveia, R. S. V., Gaião e Barbosa, A. A. G., Gouveia, V. V., \& Barbosa, G. A. (2004). Depressão infantil e fracasso vs sucesso escolar: Um estudo correlacional. Psico, 35, II 15-124.

Gouveia, V. V., Diniz, P. K. C., Santos, W. S., Gouveia, R. S. V., Cavalcanti, J. P. N., \& Medeiros, E. D. (2007). Metas de realização entre estudantes do ensino médio: Evidências de validade de uma medida. Manuscrito submetido à publicação.

Hayton, J. C., Allen, D. G., \& Scarpello, V. (2004). Factor retention decisions in exploratory factor analysis: A tutorial on parallel analysis. Organizational Research Methods, 7, 191-205.

Index Psi. (2007). Atitudes frente à escola. Disponível: http:// www.bvs-psi.org.br/ (consultado em I 5 de janeiro).

Kelloway, E. K. (1998). Using LISREL for structural equation modeling: A researcher's guide. Thousand Oaks: Sage Publications.

LDB. (1996). Lei de Diretrizes e Bases da Educação - Lei n 9.394/96. Brasília, DF: Ministério da Educação. Disponível: http://www.presidencia.gov.br/ccivil_03/Leis/L9394.htm (consultado em 24 de janeiro de 2007).

Ledesma, R, Ibañez, G. M., \& Mora, P. V. (2002). Análisis de consistencia interna mediante Alfa de Cronbach: Un programa basado en gráficos dinâmicos. Psico-USF, 7 , 143-152.

Mahoney, A. A. \& Almeida, L. R. (2005). Afetividade e processo ensino-aprendizagem: Contribuições de Henri Wallon. Psicologia da Educação, 20(I), I I-30.

Moreno, M. C. \& Cubero, R. ( I 995). Relações sociais nos anos pré-escolares: Família, escola, colegas. Em C. Coll, J. Palácios \& A. Marchesi (Orgs.), Desenvolvimento psicológico e educação: Psicologia evolutiva (vol. I, pp. 190-202). Porto Alegre: Artmed.
Mueller, D. J. ( 1986). Measuring social attitudes: A handbook for researchers and practitioners. New York: Teachers College Press.

Myers, D. G. (2000). Psicologia social. Rio de Janeiro: Livros Técnicos e Científicos.

Nunnally, J. C. (1991). Teoría psicométrica. México: Trillas.

O'Connor, B. P. (2000). SPSS and SAS programs for determining the number of components using parallel analysis and Velicer's MAP test. Behavior Research Methods, Instruments, and Computers, 32, 396-402.

Oliveira, K. L., \& Santos, A. A. A. (2005). Avaliação da aprendizagem na universidade. Psicologia Escolar e Educacional, 9, 37-46.

Oviedo, H. C., \& Campo-Árias, A. (2005). Aproximación al uso del coeficiente alfa de Cronbach. Revista Colombiana de Psiquiatría, 34(4), 527-580.

Pasquali, L. (2003). Psicometria: Teoria dos testes na psicologia e na educação. Petrópolis: Vozes.

Ribas Jr., R. C., Moura, M. L. S., \& Hutz, C. S. (2004). Adaptação brasileira da Escala de Desejabilidade Social de Marlowe-Crowne. Avaliação Psicológica, 3, 83-92.

Rodrigues, A. (1 994). Psicologia social. Petrópolis: Vozes.

Silva, C. B., Brito, M. R. F., Cazorla, I. M., \& Vendramini, C. M. M. (2002). Atitudes em relação à estatística e à matemática. Psico-USF, 7, 21 9-228.

Sisto, F. F., \& Pacheco, L. (2002). Estudo Exploratório para construção de um instrumento de ajustamento social. Psicologia em Estudo, 7, 83-90.

Sharma, A. R., Mcgue, M. K., \& Benson, P. L. (1996). The emotional and behavioral adjustment of United States adopted adolescents: Part I. An Overview. Children and Youth Services Review, 18, 83-100.

Suehiro, A. C. B. (2006). Dificuldade de aprendizagem da escrita num grupo de crianças do ensino fundamental. Psic: Revista de Psicologia da Vetor Editora, 7, 59-68.

Tabachnick, B. G., \& Fidell, L. S. (1996). Using multivariate statistics. Needham Heights: Allyn \& Bacon.

Tiba, I. (2002). Quem ama educa. São Paulo: Gente.

Tonelotto, J. M. F. (1998). Atenção e sua relação com atitudes de crianças no contexto escolar. Tese de Doutorado, Universidade Estadual de Campinas, Campinas.

Van de Vijver, F., \& Leung, K. (1997). Methods and data analysis for cross-cultural research. Thousand Oaks: Sage Publications. 
Watkins, D. (1989). The role of confirmatory factor analysis in cross-cultural research. International Journal of Psychology, 24(6), 685-701.
Willms, J. D. (2003). Student engagement at school: a sense of belonging and participation. Disponível: http://www.oecd.org/ document (consultado dia 20 de dezembro de 2006).

Recebido em: 12/03/2007

Revisado em: 06/06/2007

Aprovado em: 12/06/2007

Sobre os autores:

Patrícia Nunes da Fonseca (patynfonseca@hotmail.com) - Doutoranda em Psicologia Social pela Universidade Federal da Paraíba e Psicóloga Clínica.

Valdiney V. Gouveia (vvgouveia@pesquisador.cnpq.br) - Doutor em Psicologia pela Universidade Complutense de Madri e Professor Adjunto IV da Universidade Federal da Paraíba.

Rildésia S. V. Gouveia (rildesia.val@hotmail.com) - Doutoranda em Psicologia Social pela Universidade Federal da Paraíba.

Carlos Eduardo Pimentel (cedups@bol.com.br) - Mestre em Psicologia Social pela Universidade Federal da Paraíba.

Emerson Diógenes de Medeiros (diogenesmedeiros@yahoo.com.br) - mestrando em Psicologia Social pela Universidade Federal da Paraíba.

Endereço para correspondência:

Patrícia Nunes da Fonseca

Rua: Silvino Chaves, 625, apto. 402 - Manaíra

58.038-420. João Pessoa, PB.

Nota dos autores:

A presente pesquisa contou com o apoio do CNPq através das bolsas de Doutorado e Produtividade em Pesquisa, concedidas ao primeiro e segundo autores, respectivamente. 